\title{
Cheilitis granulomatosa associated with lupus erythematosus discoid and treated with methotrexate: report of a case*
}

\author{
Gianluca Nazzaro ${ }^{1}$ \\ Carlo Giovanni Carrera ${ }^{1}$ \\ Raffaele Gianotti ${ }^{1}$
}

\author{
Simona Muratori ${ }^{1}$ \\ Antonella Coggi ${ }^{1}$
}

DOI: http:/ / dx.doi.org/10.1590/abd1806-4841.20153762

\begin{abstract}
A bstract: We present the rare case of a 47-year-old patient, suffering from cheilitis granulomatosa and lupus erythematosus discoid: this association is really exceptional because only once reported in English literature. In addition, the treatment of cheilitis granulomatosa is a challenge for the dermatologist: the gold standard, represented by steroids, is in fact designed as a short-time option. Our report confirms the good efficacy of methotrexate as a steroid-sparing agent.
\end{abstract}

Keywords: Lupus erythematosus, discoid; Melkersson-Rosenthal Syndrome; Methotrexate

\section{INTRODUCTION}

Miescher cheilitis is a chronic condition of unknown aetiology, clinically characterized by recurrent or persistent swelling of one or both lips and histologically by non necrotizing granulomas. Its therapy is usually a challenge for dermatologists: the first choice is based on steroids, but, unfortunately, the result is temporary and additional therapy is necessary.

We present a rare case of cheilitis granulomatosa associated with lupus erythematosus discoid, treated with methotrexate with complete resolution.

\section{CASE REPORT}

A 47-year-old white man attended our Department complaining about a persistent painless swelling of the upper lip, present for five years. The patient referred that at the onset this enlargement was episodic but recurrent. Family and personal history was completely negative.

Physical examination revealed a homogeneous swelling of the upper lip, without clinical signs of erythema or edema of tongue and pharynx. Furthermore, in the same area, there were some erythematous lesions, characterized also by closely adherent scales, that had appeared only one year before (Figure 1). Other smaller erythematous lesions were present on the neck, while on the shoulders there were some achromic and scarring lesions. Two skin biopsies for histopathological examination were performed.

Histopathological examination of the swelling showed upper dermis vasodilation with perivascular infiltrate of lymphocytes, while in the reticular dermis non-necrotizing granulomas constituted by epithelioid cells and Langhans' type cells were observed (Figure 2). In the other histology the epidermis was atrophic and characterized by hyperkeratosis and vacuolar degeneration of the basal cells (Figure 3). The upper dermis showed a perivascular and periadnexal infiltrate of lymphocytes, while a large amount of mucin was seen among collagen bundles.

Laboratory exams, including immunological markers, were totally negative or within normal range.

Our diagnosis was cheilitis granulomatosa, associated with lupus erythematosus discoid.

We treated the patient with hydroxychloroquine and methylprednisolone with prompt resolution of lupus, but during reduction of the steroid there was a

Received on 10.06.2014.

Approved by the Advisory Board and accepted for publication on 15.07.2014.

Work performed at the Dipartimento di Fisiopatologia medico-chirurgica e dei trapianti, Università degli Studi di Milano - Fondazione IRCCS Ca' Granda Ospedale Maggiore Policlinico - Milano, Itália.

Financial Support: None.

Conflicts of Interest: None.

1 Università degli Studi di Milano - Fondazione IRCCS Ca' Granda Ospedale Maggiore Policlinico - Milano, Itália.

(C)2015 by Anais Brasileiros de Dermatologia 


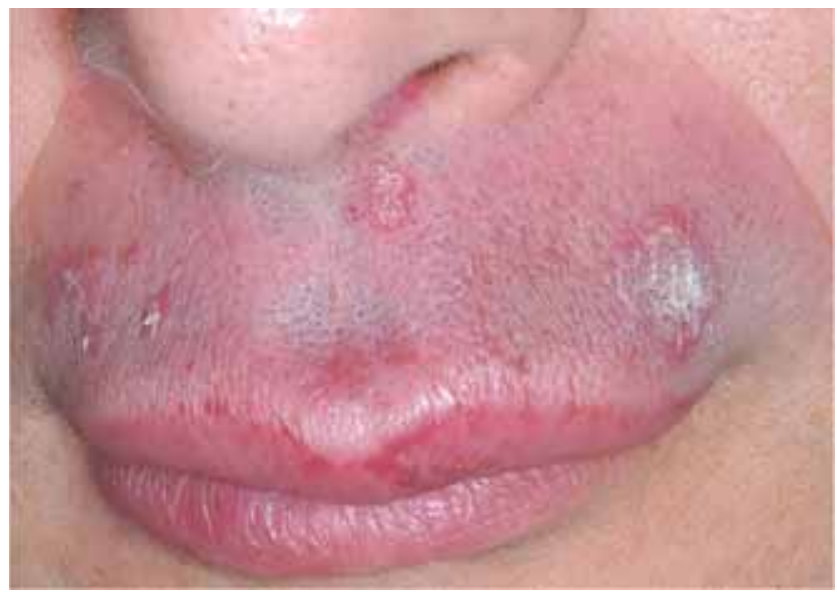

Figure 1: Persistent swelling of the upper lip, associated with erythematous-desquamative lesions

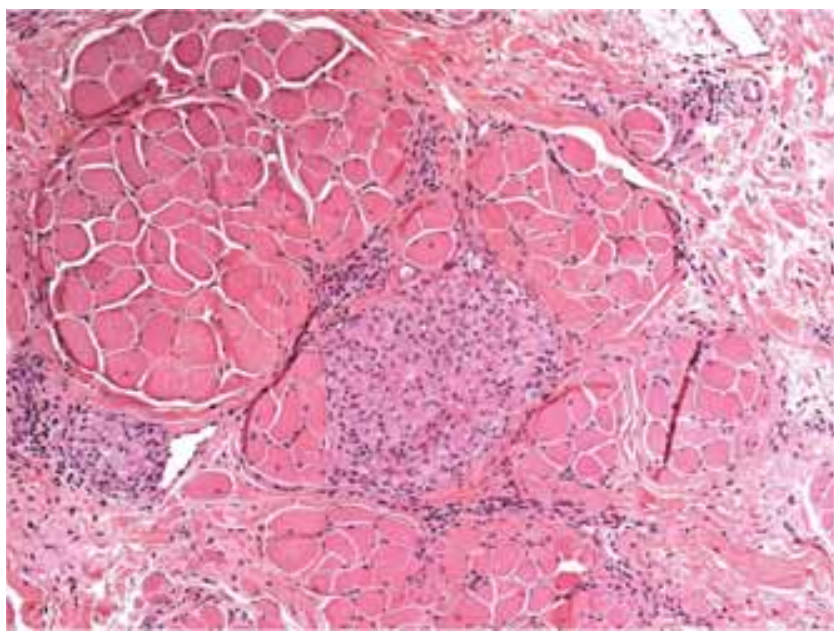

FiguRE 2: Non necrotizing granulomas in the reticular dermis [H-E 20x]

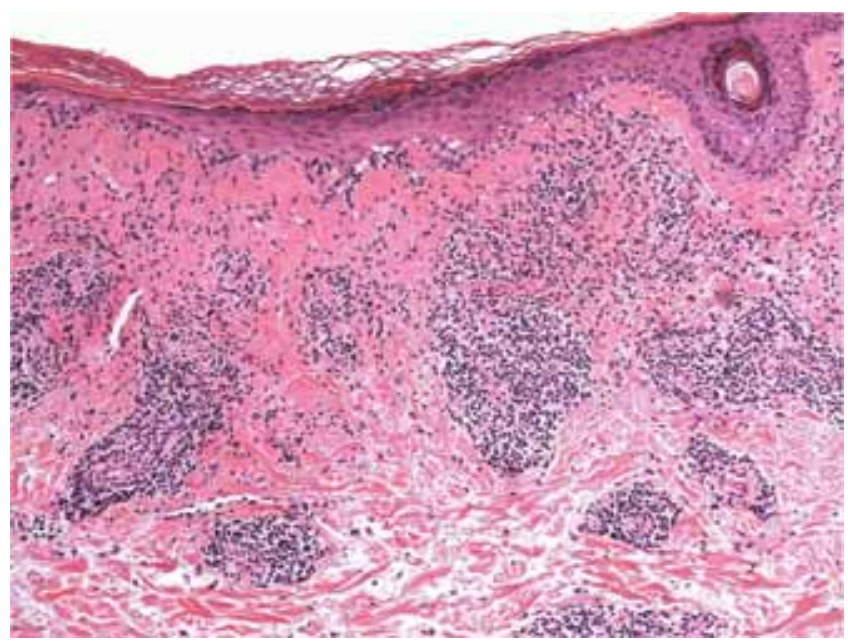

FIgURE 3: Atrophic epidermis with hyperkeratosis and vacuolization of the basal layer. In the dermis, perivascular infiltrate and deposit of mucin among collagen bundles [H-E 10x] new episode of swelling. Therefore, we added methotrexate $15 \mathrm{mg}$ per week for six months, then reduced to $10 \mathrm{mg}$ per week for two years. No relapses were reported by the patient during a three-year follow-up.

\section{DISCUSSION}

Miescher cheilitis is a condition of unknown aetiology characterized by recurrent or persistent swelling of one or both lips. It was described by Guido Miescher in 1945, after Melkersson and Rosenthal recognized the syndrome that nowadays holds their name in $1933 .{ }^{1}$ This syndrome, in fact, is composed of three symptoms: cheilitis granulomatosa, paralysis of facial nerve and fissured tongue. Miescher, several years later, noticed that in many cases cheilitis was not followed by the other two conditions and therefore considered it as a unique manifestation. Nevertheless, it should be stressed that the simultaneous presence of two or three elements of the syndrome is very uncommon and therefore Miescher cheilitis may be considered sometimes as a temporaneous diagnosis. ${ }^{2}$

Cheilitis granulomatosa is a rare inflammatory granulomatosus disease, characterized by non caseating granulomas, vasodilation and perivascular lymphocytic infiltrate. In the histological differential diagnosis, Crohn disease, sarcoidosis and infectious mycobacterial conditions must be included. Furthermore, some authors consider cheilitis granulomatosa as the extraintestinal form of Crohn disease, preceding or following the diagnosis of intestinal disease of several years and suggesting to rule out inflammatory bowel disease in case the patient complains of gastrointestinal symptoms. ${ }^{3,4}$

The first manifestation of cheilitis granulomatosa is a painless swelling involving one or both lips: this episode may resolve in a few hours and a relapse may occur in the following days. The episodes may increase in duration until they become persistent. Sometimes, the swelling is accompanied by headache, mild fever and other non specific symptoms.

To confirm the diagnosis, a biopsy for histopathological examination is necessary. In early stages, only perivascular infiltrate and edema of the upper dermis are found, while in chronic stages, non necrotizing granulomas composed of epithelioid cells are present in the reticular dermis.

As the causative mechanisms are unclear, probably a polyetiological interplay of environmental exposures and genetic predisposition, the therapy is actually a challenge to dermatologists: in English literature, there are nowadays only a few case reports or small case series, with no comparative trials. The golden standard is usually based on steroids: intralesional triamcinolone has been suggested by many authors as the first choice therapy, followed by topical clobetasol 
and systemic steroids. ${ }^{5}$ Nevertheless the result is temporary and this kind of therapy must be stopped after a while for the well known side effects; therefore, additional therapy is necessary. Other options are clofazimine, antibiotics such as tetracycline and metronidazole, immunomodulators, such as infliximab, thalidomide, dapsone and methotrexate. ${ }^{6}$

Our case is really exceptional because of the association, very rare in English literature, of cheilitis granulomatosa and lupus erythematosus discoid: to our knowledge, it has been reported only once. ${ }^{7,8}$ This association could help to clarify the pathogenesis of cheilitis granulomatosa as an immunological disease but further studies are required.

The second reason for interest is the therapy we chose. Initially we treated our patient with systemic steroid, as suggested by most reports, but at the dose reduction a relapse was recorded. A new systemic therapy was administered that could also be used with lupus erythematosus discoid: hydroxychloroquine and methotrexate, with a ready benefit. Our case, therefore, represents another evidence of the effectiveness of methotrexate as a steroid-sparing drug in cheilitis granulomatosa.

\section{REFERENCES}

1. Miescher G. Über essentielle granulmatöse Makrocheilie (Cheilitis granulomatosa). Dermatologica. 1945;91: 57-85

2. van der Waal RI, Schulten EA, van de Scheur MR, Wauters IM, Starink TM, van der Waal I. Cheilitis granulomatosa. J Eur Acad Dermatol Venereol. 2001;15:519-23.

3. Dupuy A, Cosnes J, Revuz J, Delchier JC, Gendre JP, Cosnes A. Oral Crohn disease. Arch Dermatol. 1999:135:439-42.

4. Kano Y, Shiohara T, Yagita A, Nagashima M. Association between cheilitis ganulomatosa and Crohn's disease. J Am Acad Dermatol. 1993;28:801.

5. Bacci C, Valente ML. Successful treatment of cheilitis granulomatosa with intralesional injection of Triamcinolone. J Eur Acad Dermatol Venereol. 2010;24:363-4.

6. Banks T, Gada S. A comprehensive review of current treatments for granulomatous cheilitis. Br J Dermatol. 2012;166:934-7.

7. Elias MK, Mateen FJ, Weiler CR. The Melkersson-Rosenthal syndrome: a retrospective study of biopsied cases. J Neurol. 2013;260:138-43.

8. Binckley GW. Melkersson-rosenthal syndrome with associated features of chronic discoid lupus erythematosus and sarcoidosis. Arch Dermatol. 1964;90:111.

9. van der Waal RI, Schulten EA, van der Meij EH, van de Scheur MR, Starink TM, van der Waal I. Cheilitis granulomatosa: overview of 13 patients with long-term follow-up--results of management. Int J Dermatol. 2002;41:225-9.

10. Tonkovic-Capin V, Galbraith SS, Rogers RS 3rd, Binion DG, Yancey KB. Cutaneous Crohn's disease mimicking Melkersson-Rosenthal syndrome: treatment with methotrexate. J Eur Acad Dermatol Venereol. 2006;20:449-52.

\author{
M AILING ADDRESS: \\ Gianluca N azzaro \\ Dipartimento di Fisiopatologia medico-chirurgica e \\ dei trapianti \\ U niversità degli Studi di M ilano \\ Fondazione IRCCS Ca' Granda Ospedale Maggiore \\ Policlinico \\ Via Pace, 9 - M ilano \\ E-mail: gianluca.nazzaro@gmail.com
}

How to cite this article: Nazzaro G, Muratori S, Carrera CG, Coggi A, Gianotti R. Cheilitis granulomatosa associated with lupus erythematosus discoid and treated with methotrexate: report of a case. An Bras Dermatol. 2015;90(3 Suppl 1):S197-9. 